their own countries. A successful prevention method that will help to control the outbreak in Africa will need to be achieved by taking into consideration the social, economic and behavioral context of the African population.

Intensive and well-designed campaigns promoting adherence to public-health measures and active engagement in efforts to prevent spread are urgently needed. When the first cases were declared in African countries, it was reported that several patients fled the healthcare system to seek traditional or herbal medications because of a lack of trust in westernized medicine. The use of traditional medicine is a common practice that should be discouraged in this context.

Africa can also take a lesson from the USA, which attributes the rapid spread of the virus to misinformation and erroneous faulty beliefs and rhetoric that lowered people's perception of their risk ${ }^{17}$. Traditional and religious chiefs may have a major role to play in conjunction with local healthcare organizations and/or authorities.

Deploying well-trained mobile intervention groups that can provide in-home intervention (testing for SARS-CoV-2 and help in practicing the hygiene and safety policy) will help to prevent large crowds at hospitals, which overwhelm healthcare systems.

Africa is well equipped to control the situation if countries are able to apply fast and thorough contract tracing and monitoring, and ensure quarantine for potentially infectious contacts. Such an attitude has been shown to be the key in halting the Ebola outbreak very quickly in Nigeria ${ }^{18}$.

In conclusion, there is reason for hope in Africa's response to COVID-19. The pessimistic outlook and prediction of the pandemic in Africa can-and should-be prevented. To this end, African countries should keep implementing rapid action and remain vigilant in the upcoming weeks.

\section{Bamba Gaye (D) ${ }^{1,2 \bowtie}$, Stéphanie Khoury ${ }^{1,2}$, Crystal W. Cene $e^{1,3,4}$, Samuel Kingue 1,5 Roland N'Guetta ${ }^{1,6}$, Camille Lassale (iD) 7 ,} Dadhi Baldé1,8, Ibrahima Bara Diop ${ }^{1,9}$ Jennifer Beam Dowd ${ }^{10}$, Melinda C. Mills ${ }^{10}$ and Xavier Jouven 1,2,11

${ }^{1}$ The African Research Network, Kumasi, Ghana. ${ }^{2}$ Université de Paris, Integrative Epidemiology of Cardiovascular Diseases, Paris Cardiovascular Research Center-INSERM U970, Paris, France. ${ }^{3}$ Department of Medicine, Division of General Internal Medicine, University of North Carolina at Chapel Hill, Chapel Hill School of Medicine, Chapel Hill, NC, USA. ${ }^{4}$ Cecil G. Sheps Center for Health Services Research, University of North Carolina at Chapel Hill School of Medicine, Chapel Hill, NC, USA. ${ }^{5}$ University of Yaoundé, Ministry of Public Health, Yaoundé, Cameroon. ${ }^{6}$ Institute of Cardiology of Abidjan, Abidjan, Côte d'Ivoire. ${ }^{7}$ CIBER of Pathophysiology of Obesity and Nutrition, Instituto de Salud Carlos III, Madrid, Spain. ${ }^{8}$ Department of Cardiology, University Hospital of Conakry, Conakry, Guinea. ${ }^{9}$ Cardiology Department, University Hospital of Fann, Dakar, Senegal. ${ }^{10}$ Leverhulme Centre for
Demographic Science, Nuffield College, University of Oxford, Oxford, UK. ${ }^{11}$ Cardiology Department, Georges-Pompidou European Hospital, Paris, France.

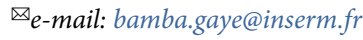

Published online: 11 June 2020

https://doi.org/10.1038/s41591-020-0960-y

References

1. Nkengasong, J. N. \& Mankoula, W. Lancet 395, 841-842 (2020).

2. Fanidi, A., Jouven, X. \& Gaye, B. Eur. Heart J. https://doi. org/10.1093/eurheartj/ehaa278 (2020).

3. Time https://time.com/5822461/coronavirus-tests-africa/ (2020).

4. Blavatnik School of Government \& University of Oxford. https://www.bsg.ox.ac.uk/research/research-projects/ coronavirus-government-response-tracker (accessed 26 April 2020).

5. Dowd, J.B. et al. Proc. Natl Acad. Sci. USA 117, 9696-9698 (2020)

6. Tan, J. et al. J. Epidemiol. Community Health 59, 186-192 (2005).

7. Chan, K. H. et al. Adv. Virol. 2011, 734690 (2011)

8. Sajadi, M.M. et al. Social Science Research Network https://doi. org/10.2139/ssrn.3550308 (2020).

9. Wang, D. et al. J. Am. Med. Assoc. 323, 1061-1069 (2020).

10. Richardson, S. et al. J. Am. Med. Assoc. 323, 2052-2059 (2020).

11. Global Health Data Exchange. http://ghdx.healthdata.org/gbdresults-tool (accessed 24 April 2020).

12. Foreman, K. J. et al. Lancet 392, 2052-2090 (2018).

13. Gaye, B. et al. BMJ Glob. Health 4, e001396 (2019).

14. Gouda, H. N. et al. Lancet Glob. Health 7, e1375-e1387 (2019).

15. Kearney, P. M. et al. Lancet 365, 217-223 (2005).

16. World Health Organization. https://www.who.int/publications-

detail/the-potential-impact-of-health-service-disruptionson-the-burden-of-malaria (2020).

17. Pew Research Center. https://www.people-press.org/2020/03/18/u-s -public-sees-multiple-threats-from-the-coronavirusand-concerns-are-growing/ (2020).

18. Fasina, F. O. et al. Euro Surveill. 19, 20920 (2014).

19. United Nations. https://population.un.org/wpp/ (2020).

20. Istituto Superiore di Sanità. https://www.epicentro.iss.it/

coronavirus/bollettino/Bollettino-sorveglianza-integrata-

COVID-19_30-marzo-2020.pdf (2020).

\title{
COVID-19 in Africa: the spread and response
}

\begin{abstract}
Given the current trends in incidence and underlying healthcare systems vulnerabilities, Africa could become the next epicenter of the COVID-19 pandemic. As the pandemic transitions to more widespread community transmission, how can the lessons learned thus far be consolidated to effectively curb the spread of COVID-19 while minimizing social disruption and negative humanitarian and economic consequences?
\end{abstract}

\section{Marguerite Massinga Loembé, Akhona Tshangela, Stephanie J. Salyer, Jay K. Varma, Ahmed E. Ogwell Ouma and John N. Nkengasong}

\footnotetext{
A s reports of COVID-19 emerged from Wuhan, China, in December 2019 (ref. $^{1}$ ), Africa started to prepare for the introduction of the first cases that would eventually arise from its close connections to China, a primary trade partner and host to more than 80,000 African students ${ }^{2}$. Statistical models based on air-travel data from China identified Egypt, Algeria and South Africa
}

as the countries at highest risk of initial introductions and spread in Africa ${ }^{3}$.

Drawing experience from the 2014 Ebola virus disease crisis in West Africa, African leaders were keenly aware that failure to contain COVID-19 would threaten health, prosperity and security ${ }^{4}$. African Union (AU) Member States rapidly focused on preventing COVID-19 importation and containing onward transmission within countries. As early as 2 January 2020, Ivory Coast $^{5,6}$, soon followed by other African countries, started implementing enhanced surveillance at airports, screening all passengers with a recent history of travel to China. In turn, most African airlines suspended direct flights to and from China? This approach initially seemed to pay off: the first COVID-19 case on the continent, with notification by Egypt on 14 February 


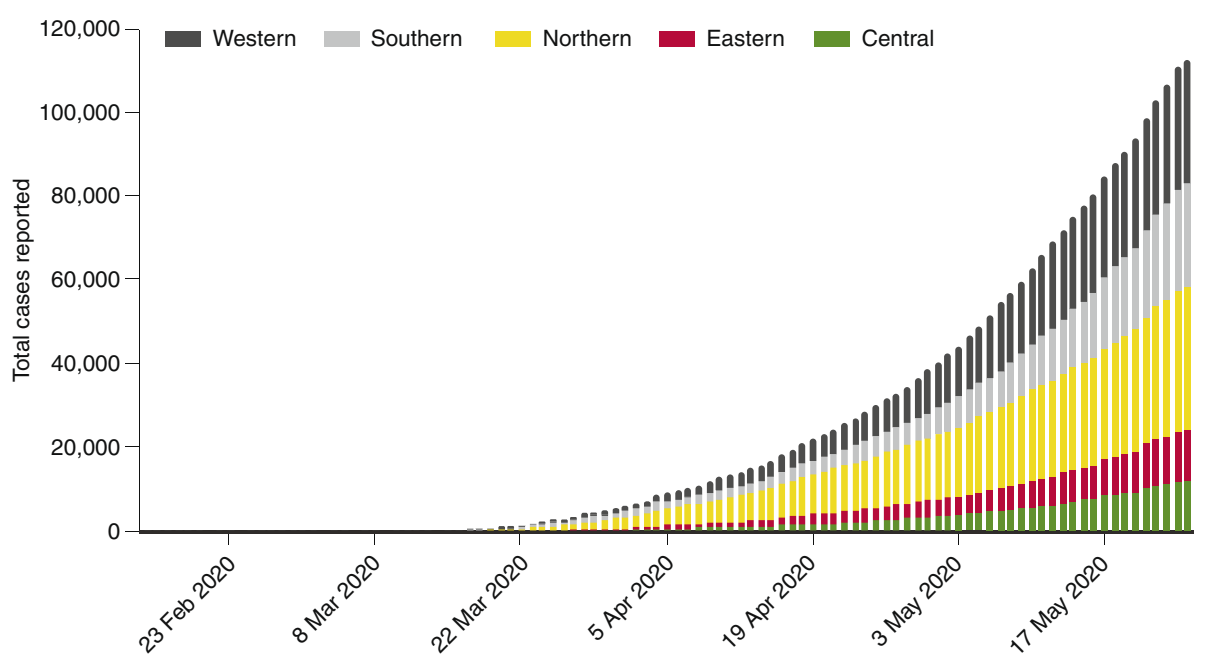

Fig. 1 | Cumulative total COVID-19 cases reported by region in Africa, 15 February to 22 May 2020.

2020, was a contact of a person with a history of travel to China. By the end of the first week of March, nine African countries (Algeria, Cameroon, Egypt, Morocco, Nigeria, Senegal, South Africa, Togo and Tunisia) were reporting over 40 cases. Most index cases originated in Europe ${ }^{8}$, where the epicenter had shifted by $13 \mathrm{March}^{9}$, and these drove early spread of the pandemic on the African continent.

\section{Status of the pandemic in Africa}

As of 22 May 2020, 54 of 55 AU Member States (except Western Sahara) had reported over 100,000 cases and 3,100 deaths. The northern region of the $\mathrm{AU}$ had provided notification of the most cases at that time, reporting over $31 \%$ (over 31,000 cases) of the cases from Africa and the highest regional case-fatality rate $(5 \%)$, with countries such as Egypt $(15,003)$, Algeria $(7,728)$ and Morocco $(7,300)$ driving the overall numbers (Fig. 1). As more countries conduct targeted mass screening and testing, these figures continue to change. Smaller continental and island AU Member States such as Djibouti and Sao Tome have been the most heavily affected, reporting over 230 and 118 cases per 100,000 population, respectively. Unlike the other African countries, both have shown epidemiological curves similar to those of severely hit countries outside Africa, such as the UK and the USA (Fig. 2). For Djibouti in particular this is probably due to a massive screening strategy initiated as the country realized its vulnerability as a commercial gateway to Africa.

To respond to COVID-19, many AU Member States have been using a combination of containment and mitigation measures to delay a surge in cases that could overwhelm the availability of hospital beds, while protecting the medically vulnerable, such as the elderly and those with comorbidities. By the end of March 2020, most countries had imposed travel bans on most affected Asian and European countries and had instituted mandatory quarantine periods for most travelers. Through April and May, more than 40 countries closed their borders, allowing only cargo, freight and the expatriation of foreign nationals. Mitigation measures, including restrictions on movement, public gatherings and schools, were also implemented. As early as 20 March 2020, AU Member States that had reported fewer than 100 cases were imposing lockdowns and curfews to prevent further COVID-19 transmission within their borders. Probably due to these early efforts, some AU Member States have seen a reduction in average daily case growth.

\section{The Africa CDC's response}

As the AU technical agency in charge of continental health security, the Africa Center for Disease Control and Prevention (Africa CDC) started monitoring reports of pneumonia coming from Wuhan in early January 2020. Africa CDC activated its Emergency Operations Center for COVID-19 on 27 January 2020 after at least four Asian countries had announced cases. Weekly virtual coordination meetings with Africa CDC Regional Collaborating Centres, ministries of health and national public-health institutions were then organized, in addition to regular press briefings and weekly briefs, to ensure timely dissemination of information about the quickly evolving outbreak. Communication was reinforced across the five AU regions by the Regional Collaborating Centres, which enabled verification of countries' alerts and reports. Data shared by countries and monitored by Africa CDC's event-based surveillance team are channeled to a live 'dashboard' that provides real-time insights into the evolution of the pandemic across AU Member States ${ }^{10}$.

As the virus was reported in Africa relatively late, the continent was afforded extra time to prepare. Africa CDC seized this window of opportunity to rapidly mobilize a continent-wide response. An emergency meeting of African health ministers held on 22 February led to adoption of the Africa Joint Continental Strategy for COVID-19 ${ }^{11}$. The strategy was approved by the Bureau of the Assembly of AU Heads of State and Government, which underpinned African leadership and ownership of the response to the outbreak. Partnerships with health agencies in sub-regional economic blocs ensured further alignment and synergies ${ }^{12}$.

Implementation of the continental strategy was led by the African Task Force for Coronavirus. A collaboration of Africa CDC, AU Member States and partners, including the World Health Organization (WHO), this task force has harnessed and leveraged existing continental expertise through technical working groups aligned to priority areas. The technical working groups review the latest evidence and best practices, adapting them into policies and technical recommendations to inform public-health action against COVID-19 and to foster coordinated preparedness and response across the continent.

Early efforts have concentrated on capacitating AU Member States for case detection and containment. Synergies among Africa CDC, the WHO and the West Africa Health Organization led to the increase in COVID-19 testing laboratories in Africa from 2 to 43 between February and mid-March $2020^{13}$. Regional workshops were conducted to strengthen the capacity of AU Members States for enhanced surveillance at points of entry, infection prevention and control, risk communication and clinical case management, with face-to-face workshops transitioning to webinars in early March as borders were closed and lockdowns were implemented.

African countries, international health agencies and partners have rallied to support implementation of the Joint Continental Strategy. In early February 2020, the Bill \& Melinda Gates Foundation committed US\$20 million to help strengthen emergency operations centers, effective surveillance and contact tracing and isolation on the 


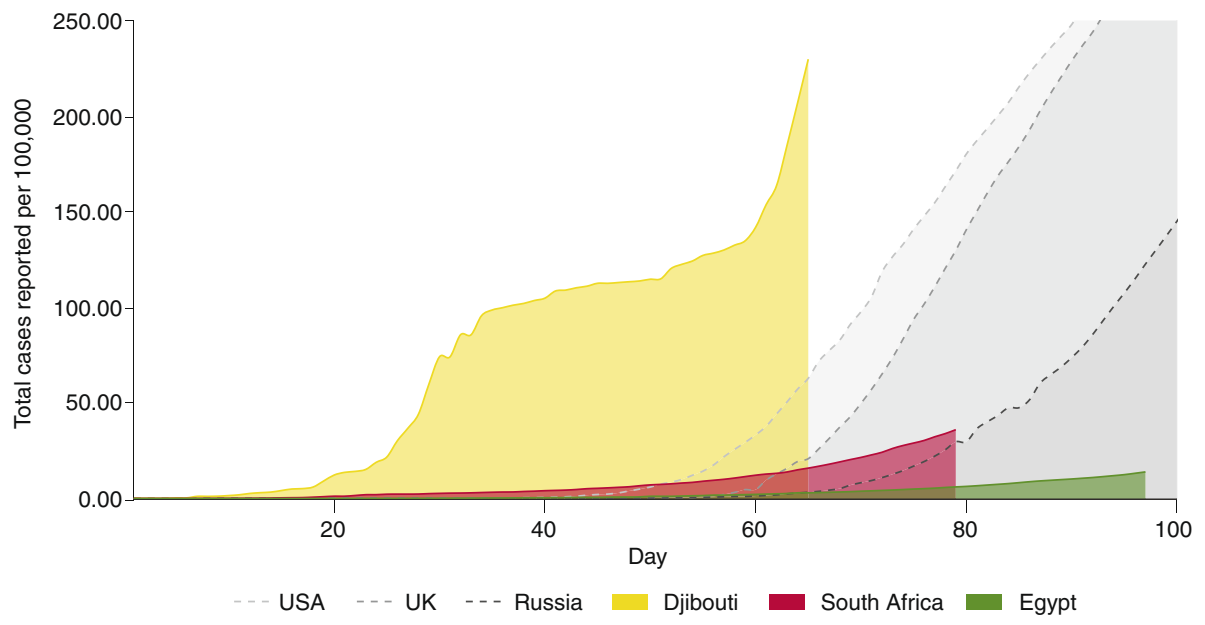

Fig. 2 | Comparison of Djibouti to countries reporting the highest number of cumulative cases per 100,000 population globally and within Africa in the first 100 days of the pandemic.

continent ${ }^{14}$, while the Ethiopian government and Jack Ma Foundation have provided medical supplies, including diagnostics, and equipment to each of the 55 countries in Africa ${ }^{15}$. In April, the AU chair announced the African Union COVID-19 Response Fund, which supports Africa CDC in equipping, training and advising public-health and healthcare delivery systems in Africa. This fund will support Africa CDC's pooled procurement of diagnostics and other medical commodities via the newly launched Partnership to Accelerate COVID-19 Testing (the 'PACT initiative').

\section{Continental strengths}

Africa has invested in preparedness and response efforts geared toward various outbreaks on the continent (such as Ebola virus disease, Lassa fever, polio, measles, tuberculosis and human immunodeficiency virus). This technical know-how has been swiftly adapted to COVID-19. Continental exchange platforms with an established wide audience have been repurposed for training and information on COVID-19 diagnostics ${ }^{16}$. Networks of community health agents that support the reponse to polio and other diseases have been leveraged for sensitization and to raise the alarm about suspected COVID-19 at the subnational level ${ }^{17}$.

Prioritization of domestic needs over exports has led to uneven distribution and shortages of essential medical supplies and has provided an impetus for boosting local manufacturing capacity ${ }^{18}$ : innovators and investors on the continent have been ramping up 'home-grown' production of key medical commodities, from masks and hands sanitizers to ventilators and mobile applications, to support triage of patients and contact tracing ${ }^{19}$.

Research on diagnostics and therapeutics is also active. The Pasteur Institute in Dakar, Senegal, has been evaluating a rapid diagnostic test that, if validated, would be moved forward for local production and distribution at an affordable price. According to clinical trials registries, by 15 May 2020, 33 clinical trials had been registered in Africa to evaluate a range of medical, supportive and behavioral interventions for COVID-19 ${ }^{20,21}$. Capacity already in place on the continent for next-generation sequencing will be expanded to ten additional centers, which will enhance surveillance of the virus and provide better understanding of transmission patterns to and within Africa ${ }^{22}$.

\section{Challenges to overcome}

An analysis conducted by the United Nations Economic Commission for Africa predicts a drop from $3.2 \%$ to $1.8 \%$ in economic growth due to the effects of the pandemic, which could ultimately push up to 27 million people into extreme poverty ${ }^{23}$. Nevertheless, given the constraints faced by most countries due to fragile healthcare systems, a catastrophic shortage of healthcare professionals $(0.2$ per 100000 in sub-Saharan Africa versus 1.5 per 100000 worldwide $)^{24}$, a drastic reduction (of 75\%) in medical commodities and supplies imports following border closures and restrictions on exports ${ }^{25}$, and financial resource limitations, the health and economic devastation anticipated is yet to unfold.

Physical-distancing measures enforced to limit transmission will also restrict access to essential non-COVID-19 healthcare services. As seen with previous Ebola virus disease outbreaks ${ }^{4}$, disruptions in the existing programs for tuberculosis, human immunodeficiency virus, malaria and vaccine-preventable diseases will cause long-lasting collateral damage on the continent.

With more people moving to urban areas, overcrowding in resource-limited settings with limited access to sanitation has increased. This poses considerable challenges for case isolation and contact tracing, which are key interventions for reducing transmission.

A recent survey conducted across 20 AU Member States looking at the implementation of public-health and social measures found that although citizens were in support of the measures, many feared prolonged extensions would lead to civil unrest $^{26}$. Community involvement in the development of any public-health or social measure needs to be a priority to ensure adherence and thus any prospective benefit.

\section{The way forward}

Faced with a public-health emergency of unprecedented scale, Africa has demonstrated solidarity and collective leadership in acting quickly. Nevertheless, the continent is still on a trajectory to meet up with global regions more affected by COVID-19 (Fig. 3). On 7 May 2020, the WHO Regional Office for Africa announced that according to its projections, 29 million to 44 million Africans could become infected in the first year of the pandemic ${ }^{27}$. Of these, an estimated 3.6 million to 5.5 million would require hospitalization, with 82,000 to 167,000 severe cases requiring oxygen and 52,000 to 107,000 critical cases requiring breathing support. Furthermore, the overall estimated COVID-19 fatality ratio $(0.66 \%)^{28}$, much lower than the current case-fatality rates within Africa (3.1\%), would indicate that as many as 470,000 people on the continent would be infected with the causative coronavirus SARS-CoV-2, with a gap of 370,000 cases missed due to insufficient testing. Together these estimates are a stark reminder that vigilance remains compulsory and that complacency cannot be allowed. Africa needs to intensify its efforts to slow the spread of the pandemic and lay the foundation for accelerated socio-economic recovery.

To ensure an effective and comprehensive response to COVID 19 on the continent, Africa CDC calls for action on the following three core areas.

AU Member States must limit transmission through systematic and widespread surveillance and testing.

The test-trace-isolate-treat strategy needs to be intensified. To achieve the PACT 


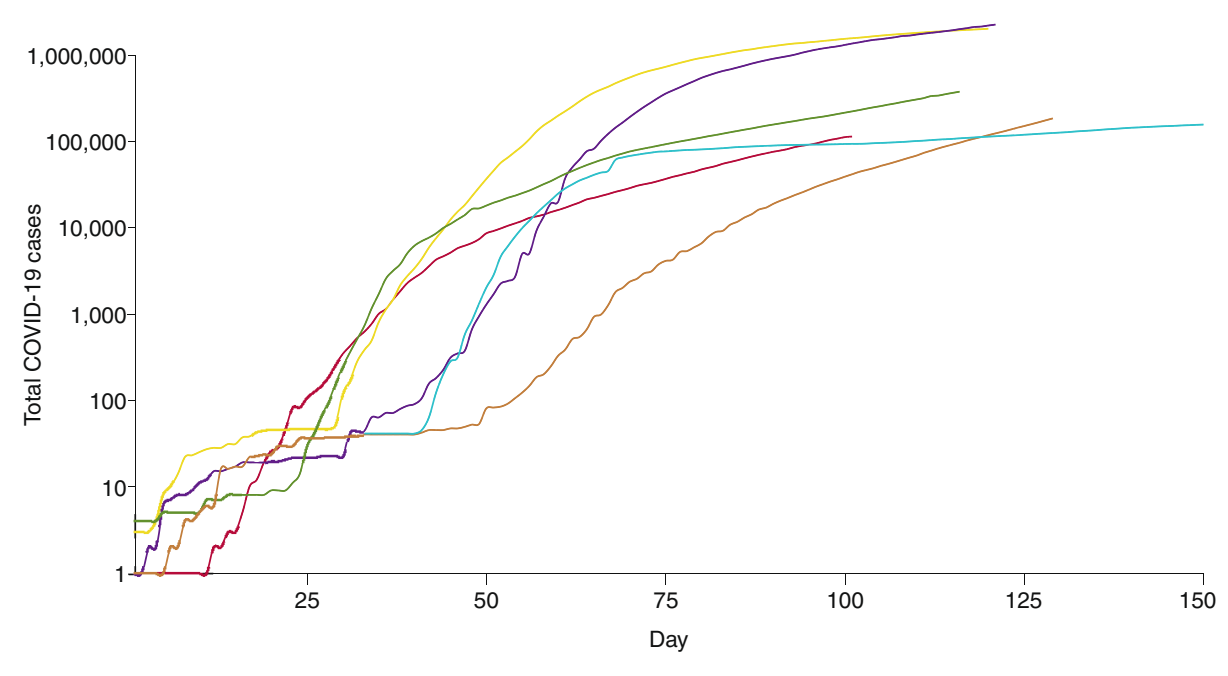

- Africa — EURO — PAHO — EMRO (w/o Africa) — SEARO — W PRO

Fig. 3 | Comparison of the cumulative total COVID-19 cases reported in the first 150 days of the pandemic in each region.

target of testing 10 million Africans within 6 months, existing testing platforms for human immunodeficiency virus and tuberculosis should be leveraged and countries should aim to fast-track the approval, adoption and rollout of innovative rapid or high-throughput diagnostics for SARS-CoV-2. To support active case finding and contact tracing within communities, public-health professionals from the Africa CDC African Health Volunteers Corps will be deployed in affected AU Member States. Surveillance for severe acute respiratory illnesses and influenza-like illness in healthcare facilities should also be enhanced ${ }^{29}$. Ultimately, these efforts will contribute to slowing transmission, will help reduce hospitalizations and will avoid overwhelming of the healthcare system.

\section{AU Member States must limit severe illness and death from COVID-19. Countries} must ensure sustained access to essential acute-care equipment and supplies in health facilities, including triage protocols, staff recruitment plans, intensive care units, oxygen, ventilators and critical-care medications. Forecasting ${ }^{28}$ is needed to inform efficient procurement and allocation of resources. Community outreach will be necessary to engage and educate populations and to encourage health-seeking behavior. Further barriers to access to COVID-19 care services in remote areas will need to be lifted with dedicated mobile treatment units.

AU Member States should grant patients access to validated and context-relevant interventions (diagnostics, therapeutics and vaccines) directed against COVID-19. A new
Science, Standards and Regulations technical working group has been set up under the African Task Force for Coronavirus, pulling together the expertise of health agencies, funders (the European \& Developing Countries Clinical Trials Partnership) and African centers and networks of excellence (such as ALERRT (https://www.alerrt.global/) and Pandora (https://www.pandora-id. net/)) to monitor the evolving COVID-19 scientific and regulatory landscape and to synthesize updates into recommendations. These will provide a framework with which to inform AU Member States for evidence-based public-health action. Pooled procurement mechanisms will contribute to safeguarding equitable access to new COVID19 diagnostics, therapeutics and vaccines in record time and at scale.

\section{AU Member States must limit social disruption and the economic consequences of COVID-19. According to the United} Nations Economic Commission for Africa, each month of lockdown puts up to $2.5 \%$ of the African gross domestic product at risk $^{25}$. AU Member States must invest in long-lasting domestic social-protection programs to shelter vulnerable households from the economic consequences of physical distancing and containment measures. Implementation of the Africa Joint Continental Strategy on COVID19 will require US $\$ 420$ million over the next six months to stop the COVID19 pandemic and tackle its immediate economic, humanitarian and health effects. Although several AU Member States and private-sector donors have pledged contributions to the AU COVID-19 response fund ${ }^{30}$, Africa will not be able to meet this demand on its own. International action and solidarity will be needed to beat COVID-19. Economic initiatives have been launched by international funding agencies, development banks, philanthropic organizations and the private sector to allocate funds to the COVID-19 response ${ }^{31}$. While these funds will undoubtedly help, it is crucial that African countries come together as one and make their voices heard to inform the choice of priorities to ensure maximum impact.

Failure to cooperate globally and to act decisively in Africa will translate into sustained transmission and pose a risk to all. As acknowledged by world leaders: only victory in Africa can end the pandemic everywhere $^{32}$.

Marguerite Massinga Loembé (iD, Akhona Tshangela, Stephanie J. Salyer, Jay K. Varma, Ahmed E. Ogwell Ouma and John N. Nkengasong ${ }^{凶}$

Africa Centres for Disease Control and Prevention, Addis Ababa, Ethiopia.

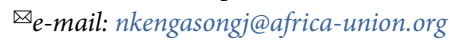

Published online: 11 June 2020

https://doi.org/10.1038/s41591-020-0961-X

References

1. Guan, W. J. et al. N. Engl. J. Med. 382, 1708-1720 (2020).

2. Le Monde https://www.lemonde.fr/afrique/article/2020/01/28/ coronavirus-1-afrique-sur-ses-gardes_6027538_3212.html (2020).

3. Gilbert, M. et al. Lancet 395, 871-877 (2020).

4. Parpia, A. S., Ndeffo-Mbah, M. L., Wenzel, N. S. \& Galvani, A. P. Emerg. Infect. Dis. 22, 433-441 (2016).

5. ACAPS https://www.acaps.org/covid

19-government-measures-dataset (2020).

6. France $24 \mathrm{https}: / / \mathrm{www}$.france24.com/fr/20200201-coronavirusla-côte-d-ivoire-prend-des-mesures-sanitaires-à-1-aéroportd-abidjan (2020).

7. Nkengasong, J. N. \& Mankoula, W. Lancet 395, 841-842 (2020).

8. Nextstrain https://nextstrain.org/ncov/africa?l=clock\&p=grid (2020).

9. World Health Organization. https://www.who.int/dg/speeches/ detail/who-director-general-s-opening-remarks-at-the-missionbriefing-on-covid-19-13-march-2020 (2020).

10. Africa CDC. https://africacdc.org/covid-19/ (accessed 10 May 2020).

11. Africa CDC. https://africacdc.org/download/africa-jointcontinental-strategy-for-covid-19-outbreak/ (2020).

12. Africa CDC. https://africacdc.org/news-item/africa-cdc-partnerswith-sacids-on-covid-19-preparedness-and-response/ (2020).

13. Nkengasong, J. Nature https://doi.org/10.1038/d41586-02001265-0 (2020).

14. Bill \& Melinda Gates Foundation. https://www.gatesfoundation. org/Media-Center/Press-Releases/2020/02/Bill-and-MelindaGates-Foundation-Dedicates-Additional-Funding-to-the-NovelCoronavirus-Response (2020).

15. Africa CDC. https://africacdc.org/news-item/africa-cdc-receivesthird-donation-of-medical-supplies-from-jack-ma-foundationco-hosts-global-medixchange-webinar-on-covid-19/ (2020).

16. African Society for Laboratory Medicine. https://aslm.org/ resource-centre/?projects=labcop\&resource_type=echo-session\& topics $=$ covid-19 (accessed 10 May 2020).

17. World Health Organization Regional Office for Africa. https://www.afro.who.int/news/nigerias-polio-community-healthagents-take-covid-19-detection (2020).

18. Setipa, J. The Telegraph https://www.telegraph.co.uk/globalhealth/science-and-disease/help-developing-countriesmanufacture-medical-equipment-solve/ (2020). 
19. Nebe, C. \& Jalloh, A.-B. DW https://www.dw.com/en/coronaviruspandemic-driving-tech-solutions-in-sub-saharan-afric a/a-53175841 (2020).

20. Africa CDC. https://africacdc.org/download/outbreak-brief18-covid-19-pandemic-19-may-2020/ (2020).

21. Africa CDC. https://africacdc.org/download/covid-19 scientific-and-public-health-policy-update-19-may-2020/ (2020)

22. Africa CDC. https://africacdc.org/news-item/illuminapartners-with-africa-cdc-to-strengthen-sequencing-capacity-forcovid-19-surveillance-in-africa/ (2020).

23. United Nations Economic Commission for Africa. https://www.

uneca.org/publications/covid-19-africa-protecting-livesand-economies (2020).

24. World Bank. https://data.worldbank.org/indicator/SH.MED PHYS.ZS (accessed 10 May 2020)
25. United Nations Economic Commission for Africa. https://www. uneca.org/publications/covid-19-lockdown-exit-strategies-africa (2020).

26. Africa CDC. https://africacdc.org/news-item/new-reportprovides-african-governments-real-time-information-andguidance-to-find-the-balance-in-covid-19-response/ (2020).

27. World Health Organization Regional Office for Africa. http:// whotogo-whoafroccmaster.newsweaver.com/JournalEnglishNews letter/16d09hirbv7 (2020)

28. Verity, R. et al. Lancet. Infect. Dis. 20, 669-677 (2020).

29. Africa CDC. https://africacdc.org/download/protocol-

for-enhanced-severe-acute-respiratory-illness-and-influenza-like-

illness-surveillance-for-covid-19-in-africa/ (2020).

30. African Union. https://au.int/en/pressreleases/20200430/africanunion-covid-19-response-fund-board-trustees-holds-inauguralmeeting (2020).
31. Cornish, L. devex https://www devex com/news/interactive-

who-s-funding-the-covid-19-response-and-what-are-th e-priorities-96833 (2020)

32. Financial Times https://www.ft.com/content/8f76a4c6-7d7alea-82f6-150830b3b99a (2020).

\section{Author contributions}

M.M.L., A.T. and S.J.S. wrote the initial manuscript draft; J.N.N. was critical in the conception and review of the manuscript; S.J.S. performed the epidemiological analysis; and all authors reviewed the final manuscript.

\section{Preserve junior faculty in biomedical sciences during and after the pandemic}

COVID-19 has disrupted scientific productivity in unquantifiable ways. Unquestionably, the biggest disruption has been felt by junior faculty. However, these bright young minds do not have to be sacrificed.

\section{Prachee Avasthi, Ushma S. Neill, Keshia M. Pollack Porter and Ashani T. Weeraratna}

$\mathrm{T}$ he COVID-19 pandemic hit as the interview season for postdoctoral researchers was reaching its apex. Universities, which have had to absorb the substantial financial losses caused by the strategies used to control the pandemic, such as lockdowns rolled out worldwide, are instituting mitigation mechanisms to retain and pay existing employees.

The ensuing cuts and hiring freezes have meant that the job market for prospective junior researchers is becoming even more competitive. For those who were in already in the interview process, 'chalk talks' were done virtually, making it harder to 'read the room'. Second visits were put largely 'on ice'. Many who have gone through the interview process are in a figurative purgatory, awaiting confirmation that they will be able to start their labs in the fall. Those unable to find a job this year will be rolling over into an even more crowded space next year as more enter the market. Many postdocs whose finite contracts are coming to an end may not have the financial means to try for academic jobs year after year, which will result in a permanent loss of this pool of talent.

For those who have managed to secure new employment, not only are job start times being delayed but also there is a risk that time-limited startup funds may be partially reclaimed or blocked from extensions. Because scientists are locked out of their labs, the collection of preliminary data is being delayed, so junior

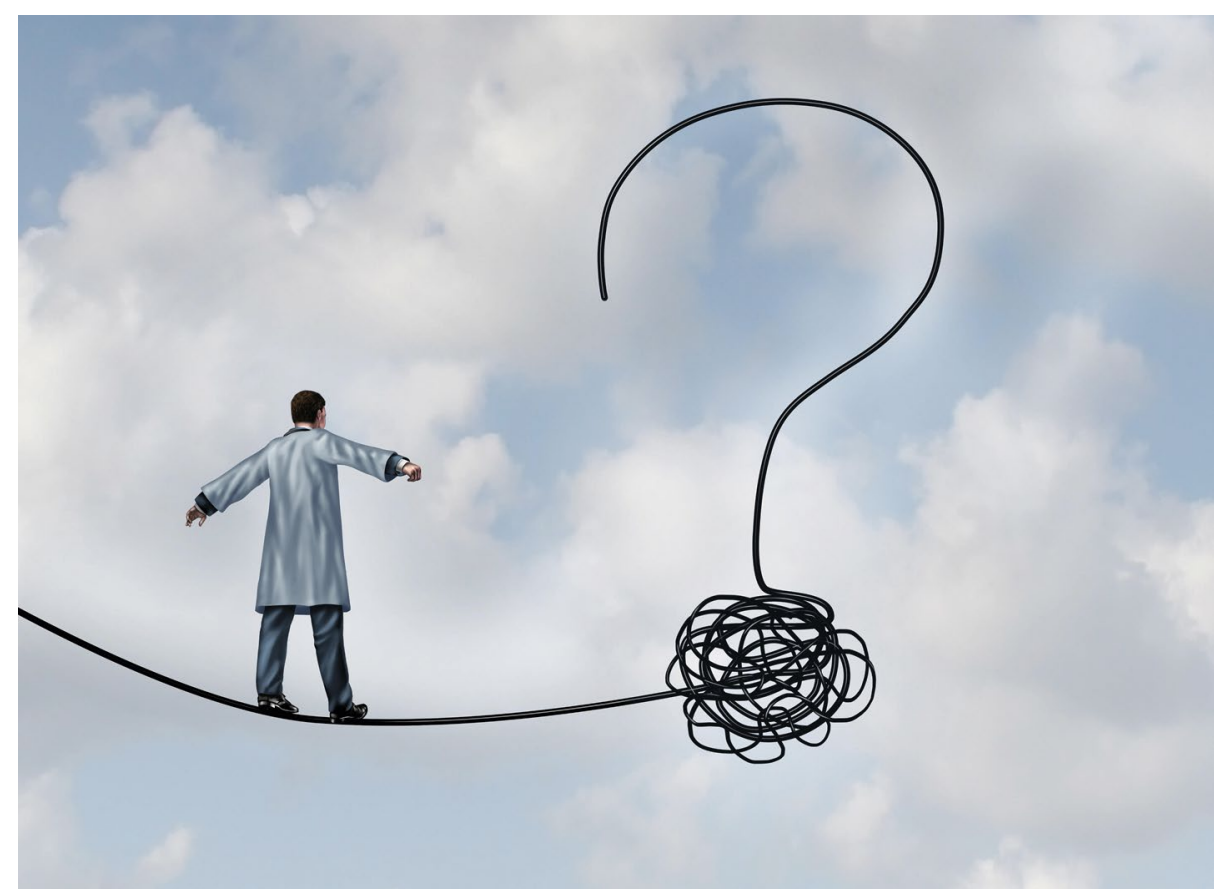

Image credit: Brain light/Alamy Stock Photo.

researchers will have less time to generate preliminary data and less time available to transition to independence. Furthermore, time to publication is also being delayed, and independent publication is needed for early-career researchers to remain competitive in the search for external grants.
However, it is not just about the data-collection time. Starting a lab is a grueling and time-consuming process for a new principal investigator that requires a period of trial and error: acquiring equipment, consumables and a reliable library of cells, samples and cultures; 